\title{
Current Status of the Critically Endangered South China Sika Deer and Its Dispersal Out of the Protected Area: Effects of Human Activity and Habitat Alteration
}

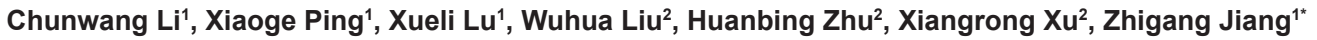 \\ ${ }^{1}$ Key Laboratory of Animal Ecology and Conservation Biology, Institute of Zoology, Chinese Academy of Sciences, Beijing 100101, China \\ 2Jiangxi Taohongling Sika Deer National Nature Reserve, Pengze 332700, China
}

\begin{abstract}
South China sika deer (Cervus nippon kopschi) is a critically endangered cervid subspecies. To learn the current status of the largest population of south China sika deer in Taohongling Nature Reserve, we monitored the changes of population size from 1980 to 2011 . Our survey indicated that deer population size in the core area of the reserve increased from 90 in 1983 to 312 in 1998, then decreased to 160 in 2005, and again increased to 275 in 2007 and 365 in 2011. We also found that many deer dispersed from the core area of reserve to the surrounding areas. The initial increase was due to the vegetation change, as when logging was stopped and other human activity was reduced after the establishing of the nature reserve, vegetation in the reserve changed from grass dominant to shrub-arbor dominant. The later decrease and dispersal of sika deer to other areas might be caused by habitat alteration and the establishment of other deer farms around the reserve. Three deer farms have been established during past four years, and the roar of the stags of captive herds of another subspecies of Cervus nippon hortulorum attracted wild south China sika deer came down the hill during the rut season. To provide better environment for wild sika deer, we suggest that: some measures such as prescribed burning and slash logging should be taken for restraining the arboreal succession in the reserve; deer farms of Cervus nippon hortulorum around the reserve should be reduced or removed; appropriate human activity such as restricted firewood collection might be allowed in the reserve.
\end{abstract}

Keywords: Cervus nippon; Dispersal; Habitat alteration; Human disturbance; Deer management

\section{Introduction}

Dispersal is one of the main factors that influence the population dynamics of animals. For the purpose of foraging or breeding, animals move from their natal territory to a new place [1-5]. However, dispersal may be risky and is often a major source of mortality [6]. When animals migrate among fragmented habitat or disperse out of the reserve, they will suffer moving through novel environments, easier be preyed by predators [1]. What is the reason for animal's dispersal out of the reserve and how to keep animals in the reserve bewildered scientists and managers. In addition, keeping animals in the reserve will reduce conflict between people and wildlife, and was considered to benefit animals as well as human beings [7].

South China sika deer (Cervus nippon kopschi) is the most endangered subspecies of all the sika deer subspecies survived in the world [8-10]. The distribution area of south China sika deer is divided into three isolated areas: Jiangxi Province, Anhui Province and Zhejiang Province in northeast part of south China. Taohongling Nature Reserve with the total area of $125 \mathrm{~km} 2$ was established to protect the largest remnant population of south China sika deer in 1981 [11]. Field surveys were conducted from 1980 to1998 [11,12]. The trend of sika deer population seemed firstly increased and then gradually decreased [13].

Highways mark the eastern, northern, and western boundaries of Taohongling Nature Reserve, while the southern border of the reserve is marked by valleys and creeks. Due to the protection practice, traffic and agricultural activities have been forbidden in the core area of Taohongling Nature Reserve since 1980. Thus, intensity of human disturbance in the core area of Taohongling Nature Reserve was mitigated than the surrounding area of the reserve. In this case, it seemed better for sika deer to stay in the reserve rather than disperse out. However, some new living sites of sika deer were found in periphery area of Taohongling Nature Reserve [14].
To learn the current status and dispersal of the largest population of south China sika deer, we conducted population surveys in the Taohongling Nature Reserve from 2006 to 2008. We compared our survey data with the survey data in the past to illustrate the changes of sika populations in the reserve. We also analyzed the factors, such as habitat alteration, deer farm and human disturbance, which may cause the dispersal of the sika deer and influence the population status of the wild sika deer population. Furthermore, we discussed the management of sika deer based on our results.

\section{Study Area and Methods}

Taohongling Nature Reserve (116 $\left.32^{\prime}-116^{\circ} 43^{\prime} \mathrm{E}, 2^{\circ} 42^{\prime}-29^{\circ} 53^{\prime} \mathrm{N}\right)$, locates in the lower ranches of the Yangtze River in Pengze County, was established to protect the largest remnant population of south China sika deer in 1981 [11]. The core area of the reserve is $26.7 \mathrm{~km}^{2}$, and the total area of the reserve is $125 \mathrm{~km}^{2}$. The altitude of the reserve varies from $100 \mathrm{~m}$ to $536 \mathrm{~m}$ above sea level. The main vegetation types are shrub land, shrub-grassland, secondary broad-leaved forest and artificial coniferous forest [11].

*Corresponding author: Zhigang Jiang*, Key Laboratory of Animal Ecology and Conservation Biology, Institute of Zoology, Chinese Academy of Sciences, Beijing 100101, China, Tel: (+86) 106480 7466;Fax: (+86) 1064807099 E-mail: jiangzg@ioz.ac.cn

Received October 15, 2013; Accepted December 06, 2013; Published December 11,2013

Citation: Chunwang Li, Ping X, Lu X, Liu W, Zhu H, et al. (2013) Current Status of the Critically Endangered South China Sika Deer and Its Dispersal Out of the Protected Area: Effects of Human Activity and Habitat Alteration. J Biodivers Endanger Species 1: 117. doi: 10.4172/2332-2543.1000117

Copyright: (c) 2013 Chunwang Li, et al. This is an open-access article distributed under the terms of the Creative Commons Attribution License, which permits unrestricted use, distribution, and reproduction in any medium, provided the original author and source are credited. 
Citation: Chunwang Li, Ping X, Lu X, Liu W, Zhu H, et al. (2013) Current Status of the Critically Endangered South China Sika Deer and Its Dispersal Out of the Protected Area: Effects of Human Activity and Habitat Alteration. J Biodivers Endanger Species 1: 117. doi: 10.4172/23322543.1000117

Page 2 of 4

We used quadrats-sampling method to take a census of the sika deer in the autumn (September and October) of 2006, 2007 and 2011. We arranged $201 \mathrm{~km}^{2}$ quadrats as observation sites in the reserve (12 quadrats), and peripheral area (8 quadrats) out of the reserve. We arranged 20 observer groups ( 2 individuals in each group), and all groups arrived at all 20 observation sites respectively at the same time of 3:30 am. We recorded the roaring and numbers of individuals and groups of sika deer in each quadrate until 9:00 am on the observation day. We calculated the population size of sika deer with the formula: $P=P n A R / A Q$. Where, $P$ represents population size of sika deer in the reserve; $P n$ represents numbers of sika deer in all quadrates; $A_{R}$ represents area of the reserve; $A_{Q}$ represents area of all quadrates.

For analyzing the cause for dispersal of sika deer, we obtained the historical data of sika deer, habitat type and human disturbance from published data $[2,3,10-13]$. We also investigated the deer farms of another subspecies of Cervus nippon hortulorum in circumjacent area of the reserve, and mapped the status of human activity in and out of the reserve.

\section{Results}

The reserve is surrounded by Huanghua, Huangling, Dongsheng and Qingshan Townships and many small villages, now a green island in a sea of extensively farmed agricultural land with a high human population density. (Figure 1)

The population size in the core area of the reserve increased from 90 in 1983 to 275 in 2007, and then to 365 in 2011, and the sika deer recorded in surrounding areas of the Taohongling Nature Reserve has increased from zero in 1983 to 46 individuals in 2007. (Table 1)

The numbers of deer farms of Cervus nippon hortulorum in surrounding area of the reserve have increased from one in 2004 to three in 2007 (Figure 1). The names of deer farms were Longgongdong (started in 2006, Free-ranging in a yard), Xiaowuchen (started in 2007, pen-feeding) and Dongsheng (started in 2004, Free-ranging in a yard) respectively. The total individuals of farmed Cervus nippon hortulorum increased from 33 deer in 2004 to 335 deer in recent year. During rut seasons in past two years, 11 individuals and some traces of wild sika deer were recorded near outside of those deer farms.

Based on published data, habitat type in the core area of the reserve has changed from grass dominant to arbor dominant. In the core area, human activities were forbidden and human disturbance approached to zero since 1980. In periphery area, human population density changed from 323 people $\mathrm{km}^{-2}$ to 226 people $\mathrm{km}^{-2}$. (Table 1 )

\section{Discussion}

Our survey showed that, since the establish year of 1981, population of south China sika deer in Taohongling Nature Reserve has increased. However, deer's dispersal out of the reserve in recent years becomes a serious problem for reserve management. The dispersal of south China sika deer might be related with three factors: habitat degradation, human disturbance and deer farms.

Among those factors, habitat quality was probably the most

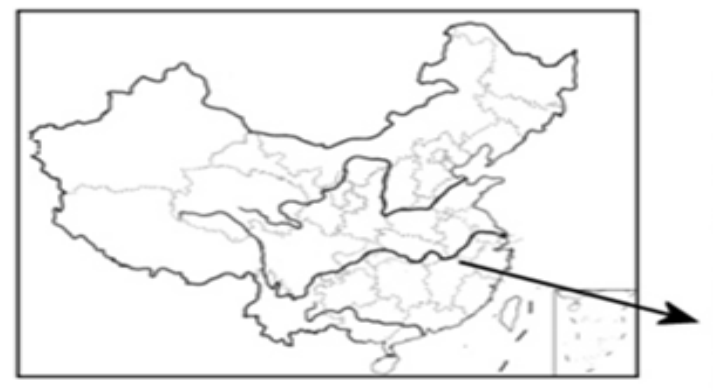

\section{Legend}
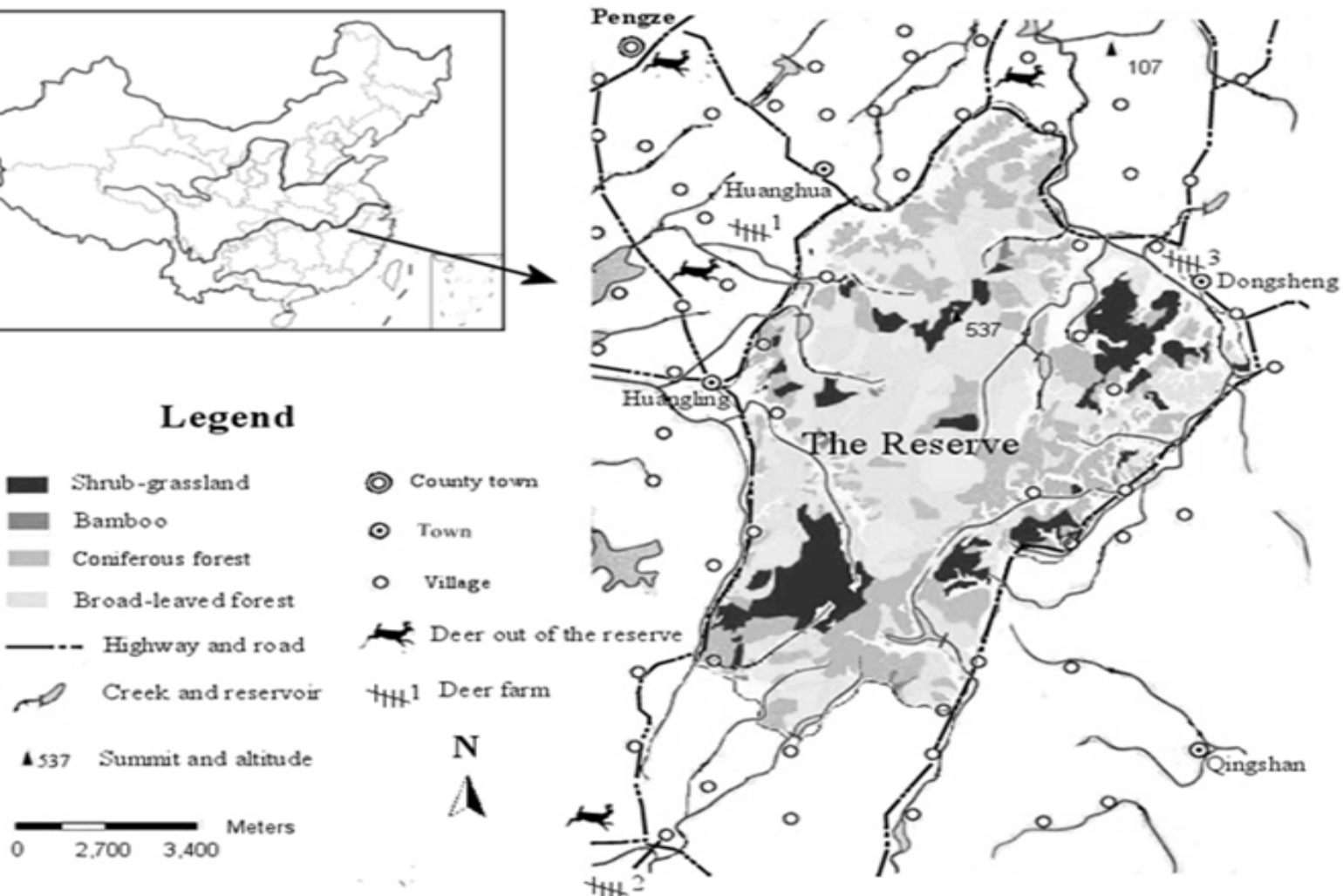

$++t^{2}$

Figure 1: Current status of human occupancy, vegetation type and deer farm in/around Taohongling Nature Reserve. The map show the vegetation type, deer farm, road and human residential area. 1. Longgongdong deer farm; 2 . Xiaowuchen deer farm; 3 . Dongsheng deer farm. The shadowy area is the Reserve in where no people live. Four main distribute sites of sika deer out of the reserve were recorded. 
Citation: Chunwang Li, Ping X, Lu X, Liu W, Zhu H, et al. (2013) Current Status of the Critically Endangered South China Sika Deer and Its Dispersal Out of the Protected Area: Effects of Human Activity and Habitat Alteration. J Biodivers Endanger Species 1: 117. doi: 10.4172/23322543.1000117

\begin{tabular}{|c|c|c|c|}
\hline & \multicolumn{2}{|c|}{ Status of changes } & \multirow[t]{2}{*}{ Data source } \\
\hline & Core protected area & Periphery area & \\
\hline $\begin{array}{l}\text { Deer } \\
\text { population }\end{array}$ & $\begin{array}{l}\text { Increased from } 90 \text { in } 1983 \text { to } \\
312 \text { in } 1998 \text {, then decreased } \\
\text { to } 160 \text { in } 2005 \text {, and again } \\
\text { increased to } 275 \text { in } 2007 \text { and } \\
365 \text { in } 2011 .\end{array}$ & $\begin{array}{l}\text { Increased from zero in } \\
1983 \text { to } 46 \text { in } 2007 .\end{array}$ & $\begin{array}{l}\text { [12] Our } \\
\text { present data. }\end{array}$ \\
\hline Habitat & $\begin{array}{l}\text { From grass dominant to } \\
\text { arbor dominant. }\end{array}$ & - & [13-14]. \\
\hline $\begin{array}{l}\text { Human } \\
\text { activity }\end{array}$ & $\begin{array}{l}\text { Human activities were forbid- } \\
\text { den and no people resided in } \\
\text { since } 1980 .\end{array}$ & $\begin{array}{l}\text { Population den- } \\
\text { sity changed from } 323 \\
\text { people km-2 to } 226 \\
\text { people km-2. }\end{array}$ & {$[2,3,12]$} \\
\hline Deer farm & No deer farm. & $\begin{array}{l}\text { Increased from zero to } \\
\text { three more. }\end{array}$ & $\begin{array}{l}\text { [12] Our } \\
\text { present data. }\end{array}$ \\
\hline
\end{tabular}

Table 1: Changes of sika deer population and influential factors that possibly induce dispersal of sika deer in Jiangxi Taohongling Nature Reserve during past 28 years (1983-2011)

important factor that resulted in the dispersal of sika deer. [13] reported that in Taohongling area, the habitats of which the Habitat Suitable Indexes (HSI) for wild sika deer were over 0.75 accounted for $18.57 \%, 8.09 \%, 15.11 \%$ and $6.55 \%$ of total habitat of the reserve in spring, summer, autumn and winter, respectively. Most of those suitable habitats are located at fringe of the core area of the reserve. [15] Suggested that sika deer populations are likely to fluctuate when the population size close to its carrying capacity. For sika deer, the maximum carrying capacity of the habitat in Taohongling Nature Reserve was not estimated. However, because of the alteration of the habitat of the reserve, the environmental carrying capacity may go down to a low value [14]. Studies on habitat selection indicated that sika deer preferred habitat of shrub and shrub-meadow with lesser shrub coverage [14]. The dense-cover arbor dominant habitat is no longer suitable for sika deer. Due to the natural succession of vegetation in the past several years, the habitat of the reserve is not so much a restored one as a degraded one for sika deer. Thus, the change of vegetation cover was the main factor that lead sika deer disperse out of the reserve. The same result was also reported in white-tailed deer Odocoileus virginianus [16].

Human disturbance affect movement of animals. For example, red deer (Cervus elaphus xanthopygus) tended to avoid areas within three kilometres of roads [17] and bed site of Przewalski's gazelle (Procapra przewalskii) was most sensitive to roads [18] in white-tailed deer, home range size and movement related to logging disturbance [16]. However, human disturbance in the core area of Taohongling Nature Reserve has been greatly reduced due to the implementation of conservation [11]. On the contrary, in surrounding areas of the reserve, wild boar trapping and domestic dog resulted frequently in the death of sika deer [19]. Moreover, because of the prohibition of logging, herding and wildfire in the core area, the vegetation restored and the habitat type changed from grass dominant one to arboreal land which is not preferred by sika deer [11-12].

Beside of the habitat alteration and human disturbance, deer farming was another factor that resulted in the dispersal of wild sika deer out of the reserve. Roar of the captive stags was found to attract wild sika deer come down from the hill. Based on our data, although the farmed sika deer is another subspecies of sika deer, we should notice the effects of sexual attraction on the wild sika deer.

\section{Management Implications}

The Intermediate Disturbance Hypothesis is an ecological hypothesis which proposes that biodiversity is highest when disturbance is neither too rare nor too frequent [20]. Although this hypothesis emphasizes the natural disturbance, human disturbance is an important type of disturbance which affects natural habitat. As for Taohongling Nature Reserve, we suppose that appropriate disturbance may inhibit the secondary succession which with the trends to arboreal forest. Selective logging and prescribed burning are the two main methods for maintaining the suitable habitat. Both methods increased the species diversity and biomass of forbs and grasses and reduced the height of shrubs and arbores [11].

The goal of management of a nature reserve is to maintain a healthy population of the target species and its suitable habitat. Forest-inhabiting deer were considered as ecological indicators of forest management and diversity [21]. That is to say, we should integrate deer management with ecosystem management [21-22]. When animals migrate among fragmented habitat or disperse out of a protected area; they will easily be preyed by predators or disturbed by humans [1] Dispersal rates in white-tailed deer could be critical to long-term success of management [23]. It will reduce conflict between human and wildlife to keep wild animals in the reserve, which was considered to benefit animals as well as human beings [7]. Our analysis indicated that habitat alteration, deer farm and deficiency of human interference possibly induced dispersal of sika deer out of the reserve.

For remaining sika deer in the reserve and protected them effectively,

\section{We suggested that:}

A. Some measures such as prescribed burning and slash logging should be taken for restraining the arboreal succession in the reserve;

B. Sika deer farms around the reserve should be reduced or removed;

C. Appropriate human activity such as schemed firewood collection should be allowed in the reserve.

\section{Acknowledgments}

This study was supported by National Nature Science Foundation of China (No. 31070348, 30670353).

\section{References}

1. Anthony LL, Blumstein DT (2000) Integrating Behaviour into wildlife Conservation: The Multiple Ways that Behaviour can reduce Ne. Biol Conserv 95:303-315.

2. China Bureau of the Census (1991) Demographic yearbook of Jiangxi Province Beijing, China.

3. China Bureau of the Census (2006) Demographic yearbook of Jiangxi Province. Beijing, China.

4. Shields WM (1987) Dispersal and mating systems: Investigating their causa connections. In; Patterns of dispersal among mammals and their effect on the genetic structure of populations. Editors D Chepko-Sade, ZT Halpin. University of Chicago Press, Chicago, USA.

5. Verhulst S, Perrins CM, Riddington R (1997) Natal Dispersal of Great Tits in a Patchy Environment. Ecology 78: 864-872.

6. van Vuren D (1998) Mammalian dispersal and reserve design. In; Behavioura ecology and conservation biology. Editors Caro T. Oxford University Press, New York, USA.

7. Hill CM (1998) Conflicting Attitudes towards Elephants around the Budongo Forest Reserve, Uganda. Environ Conserv 25: 244-250.

8. McCullough DR, Jiang ZG, Li CW (2009) Sika Deer in Mainland China. In; Sika deer: Biology and Management of Native and Introduced Populations. Editors McCullough DR, Takatsuki S, Kaji K. Springer Press, Tokyo, Japan and New York, USA. 
Citation: Chunwang Li, Ping X, Lu X, Liu W, Zhu H, et al. (2013) Current Status of the Critically Endangered South China Sika Deer and Its Dispersal Out of the Protected Area: Effects of Human Activity and Habitat Alteration. J Biodivers Endanger Species 1: 117. doi: 10.4172/23322543.1000117

9. State Forestry Administration of PR China (2001) National Engineering Construction Plan for Deer Protection. State Forestry Administration of People's Republic of China, Beijing, China.

10. Xu HF, Hou L, Sheng L, Gu CM (1998) Status and current distribution of South China sika deer. Biodiversity Science 6: 87-91.

11. Jiang Z (2009) Biodiversity and sika deer in Taohongling Nature Reserve, Jiangxi, China. Tsinghua University Press, Beijing, China.

12. Liu X (2000) Jiangxi Taohongling Sika Deer National Nature Reserve. Chinese Forestry Press, Beijing, China.

13. Liu J (2007) Food and Habitat Selection by Sika Deer (Cervus Nippon Kopschi) and Habitat Improvement in Taohongling Nature Reserve. University of Chinese Academy of Sciences, Beijing, China.

14. Fu Y, Jia X, Hu J, Guo Y, Zhu H (2006) Summer habitat selection by sika deer in Taohongling Nature Reserve, Jiangxi Province. Sichuan Journal of Zoology 25: $863-865$.

15. Kaji K, Koizumi T, Ohtaishi N (1988) Effects of resource limitation on the physical and reproductive condition of sika deer on Nakanoshima Island, Hokkaido. Acta Theriologica 33: 187-208.

16. McNulty SA (1997) Cover Type, Logging Disturbance, and Recruitment of WhiteTailed Deer in the Adirondacks. State University of New York, New York, USA.
17. Jiang G, Zhang M, Ma J (2007) Effects of Human Disturbance on Movement Foraging and Bed Site Selection of Red Deer Cervus Elaphus Xanthopygus from the Wandashan Mountains, Northeastern China. Acta Theriologica 52 435-446.

18. Li C, Jiang Z, Feng Z, Yang X, Yang J, et al. (2009) Effects of Highway Traffic on Diurnal Activity of The Critically Endangered Przewalski's Gazelle. Wildlife Research 36(5):379-385.

19. Wu H, Wu X, Gong G (2003) Current status of sika deer resource in Wanjia Town, Ningguo City, Anhui Province. Chinese Journal of Zoology 38: 54-57.

20. Connell JH (1978) Diversity in Tropical Rain Forests and Coral Reefs. Science 199: $1302-1310$

21. Hanley TA (1996) Potential Role of Deer (Cervidae) As Ecological Indicators of Forest Management. Forest Ecol Manag 88: 199-204.

22. deCalesta DS, Stout SL (1997) Relative Deer Density and Sustainability: A Conceptual Framework for Integrating Deer Management with Ecosystem Management. Wildlife Soc B 25: 252-258.

23. Porter WF, Underwood HB, Woodard JL (2004) Movement Behaviour, Dispersal, and the Potential for Localized Management of Deer in a Suburban Environment. Journal of Wildlife Management 68(2): 247-256. 